\title{
JEKK
}

Jurnal Epidemiologi Kesehatan Komunitas

$4(1), 2019,11-17$

\section{Faktor Lingkungan dan Perilaku yang Berpengaruh terhadap Kejadian Filariasis di Daerah Endemis Kota Pekalongan}

\author{
Yusuf Lensa Hamdan *, Soeharyo Hadisaputro ${ }^{* * *}$, Ari Suwondo**, Muchlis AU Sofro ${ }^{* * *}$, Mateus \\ Sakundarno Adi* \\ "Dinas Kesehatan Kota Bontang, ${ }^{* *}$ Fakultas Kesehatan Masyarakat Undip, ${ }^{* * *}$ Fakultas Kedokteran \\ Undip
}

\begin{abstract}
Background : Filariasis is a disease still become a health problem in Indonesia. South Pekalongan District is one of the endemic areas of filariasis. Filariasis is influenced by several factors such as environmental factors, sosio economic and community behavior. The objective of this study was to determine the influence of environmental factors, socio economic factor and behaviour that contributed to the incidence of filariasis cases in South Pekalongan District.

Methods : This research was an observasional research with a case-control approach. Case in this study was filariasis cases and for control was people suffer from filariasis. The number of each case and control is 40. Data was taken by observation and interview. Data collected was analyzed by using logistics regression.

Results : Multivariate analysis shows that out of 11 (eleven) variables there is 1 variable which is proven to influence the incidence of filariasis in South Pekalongan District in July 2018 , it was use of anti-mosquito drugs ( OR $=29,231$, CI 95\% $=5,998-142,445)$.

Conclusion : Not using mosquito repellent is the most dominant risk factor for the occurrence of filariasis transmission. People are advised to use mosquito repellent while sleeping or during activities at night. It is necessary to perform health promotion and extend the information related to filariasis in order to improve community knowledge.
\end{abstract}

Keywords: Filariasis, Environmental, Behavioral, South Pekalongan

*Penulis korespondensi : yusuflensahamdan@gmail.com 


\section{Pendahuluan}

Filariasis disebabkan oleh infeksi parasit nematoda yang ditularkan oleh vektor filaria. Filaria dewasa dapat hidup di limfatik, pembuluh darah, kulit, jaringan ikat atau selaput serous. ${ }^{1}$ Sampai saat ini penyakit tersebut masih menjadi masalah kesehatan masyarakat di Indonesia, baik di daerah perkotaan maupun pedesaan. Pada tahun 2014 di Indonesia dilaporkan sebanyak 29 propinsi dan 239 Kabupaten/Kota endemis filariasis, sehingga diperkirakan sebanyak $102,279,739$ orang yang tinggal didaerah endemis tersebut yang berisiko terkena filariasis. $^{2}$

Kota Pekalongan merupakan daerah yang banyak ditemukan kasus kronis filariasis. Berdasarkan laporan diketahui bahwa jumlah kasus filariasis yang ditemukan, dari dua belas kecamatan hanya satu kecamatan yang masih menjadi daerah endemis filariasis, yaitu Kecamatan Pekalongan Selatan dari tahun 2014 $2016 .^{3}$

Upaya - upaya penanggulangan telah dilakukan terhadap penderita filariasis di Kota Pekalongan, antara lain dengan pengobatan penderita dengan menggunakan diethylcarbamazine (DEC) dosis 1 tablet per tahun selama 5 tahun, pengendalian vektor dengan fogging memakai insektisida organophospat dan sintetic pyretroid serta penyuluhan di setiap Posyandu oleh petugas Puskesmas terutama sebelum kegiatan pengobatan massal dilakukan. ${ }^{3}$ Namun kegiatan tersebut masih menemui beberapa kendala, antara lain belum diketahuinya tempat tempat perindukkan nyamuk serta berbagai faktor yang mendukung penyebaran filariasis di wilayah tersebut seperti faktor perilaku dimana sebagian masyarakat Kota Pekalongan biasa keluar rumah pada malam hari hanya untuk berkumpul makan diluar ataupun memang berkegiatan menjaga keamanan desa, mengikuti kegiatan pengajian, menjahit pada malam hari dan tidak semua masyarakat menggunakan pakaian yang melindungi dari gigitan nyamuk. ${ }^{3}$

Oleh karena itu perlu diteliti mengenai berbagai faktor lingkungan dan perilaku yang berpengaruh terhadap kejadian filariasis (studi kasus daerah endemis di Kota Pekalongan) tahun 20142016.

\section{Metode}

Rancangan penelitian yang akan digunakan Case Control Study, desain tersebut dipilih karena sesuai dengan tujuan penelitian yaitu menganalisis berbagai faktor lingkungan dan perilaku yang berpengaruh terhadap terjadinya suatu penyakit. ${ }^{4}$ Besar sampel dari penelitian ini dihitung menggunakan rumus Stanley Lameshow ${ }^{5}$ :

$$
\begin{gathered}
P_{1}=\frac{(O R) P_{2}}{(O R) P_{2}+\left(1-P_{2}\right)} \\
n=\frac{Z^{2}{ }_{1}-\alpha / 2\left[1 /\left[P_{1}\left(1-P_{1}\right)\right]+1 /\left[P_{2}\left(1-P_{1}\right)\right]\right\}}{[\operatorname{In}(1-\varepsilon)]^{2}}
\end{gathered}
$$

Dari perhitungan besar sampel dengan menggunakan rumus di atas diperoleh 40. Pengambilan sampel dilakukan dengan purposive sampling sesuai kebutuhan peneliti berdasarkan total populasi. Jumlah kasus dalam penelitian ini adalah 40 orang yang didapat dari data Dinas Kesehatan Kota Pekalongan. Tahun 2014-2016. Penelitian mengambil perbandingan antar kasus dan kontrol 1:1 maka jumlah kontrol adalah 40 orang. Jumlah sampel keseluruhan dalam penelitian ini adalah 80 orang.

Pelaksanaan kegiatan analisis data sekunder dilakukan dengan mengumpulkan data mengenai keadaan wilayah (meliputi topografi, batas-batas wilayah dan iklim; perumahan, meliputi jumlah rumah dan letak rumah); penduduk, (meliputi jumlah keluarga, nama kepala keluarga, jumlah anggota keluarga, pembagian penduduk menurut umur dan kelamin, serta jenis pekerjaan dan pendidikan). 
Wawancara sikap dan perilaku masyarakat terhadap filariasis. Pengumpulan data dilakukan lewat wawancara terstruktur dengan menggunakan kuesioner. Sebagai responden penelitian ini adalah:

a. Bersedia berpartisipasi dalam penelitian.

b. Tercatat sebagai penderita filariasis yang tercatat di Puskesmas dan Dinas Kesehatan.

c. Sudah berdomisili ditempat dimana ia tercatat sebagai sampel minimal selama tiga tahun.

d. Berdasarkan pemeriksaan mikroskopis pada sediaan darah jari dapat dinyatakan positif maupun negatif mikrofilaria.

Analisis hasil yang dilakukan terdiri dari analisis deskriptif, bivariat dan multivariate. Analisis deskriptif untuk memberikan gambaran dan keadaan variabel penelitian. Analisis bivariat dan multivariat untuk menguji hubungan antara faktor individu (jenis kelamin, umur dan pekerjaan) penduduk, keadaan lingkungan sekitar pemukiman dan perilaku penduduk (sikap dan kebiasaan) penduduk terhadap penularan filariasis di Kelurahan Kuripan Kertoharjo dan Kelurahan Jenggot, Kecamatan Pekalongan Selatan, Kota Pekalongan.

Analisis ini mempergunakan program SPSS, maka analisis bivariat dan multivariat akan dapat diperoleh tingkat signifikansinya dengan ketentuan jika $\mathrm{p}=0,05$, maka terdapat hubungan yang signifikan, jika $p>0,05$, maka tidak ada hubungan yang signifikan.

Penelitian ini mendapat kelaikan etik dari Komisi Etik Penelitian Kesehatan Fakultas Kedokteran Universitas Diponegoro dan RSUP dr. Kariadi Semarang.

\section{Hasil Penelitian}

Kecamatan Pekalongan Selatan memiliki 5 wilayah administrasi Kelurahan yaitu Kelurahan Jenggot, Kelurahan
Banyurip, Kelurahan Buaran Kradenan, Kelurahan Kuripan Kertoharjo, Kelurahan Yosorejo, Kelurahan Soko Duwet. ${ }^{6}$ Kelurahan Kuripan Kertoharjo dan Kelurahan Jenggot merupakan kelurahan yang dipilih sebagai subyek penelitian karena berdasarkan hasil survei pendahuluan ditemukan kasus filariasis selama tiga tahun berturut-turut pada tahun 2014- 2016.

Berdasarkan pengamatan di lapangan didapatkan pada kelompok kasus dan kontrol sebagian besar responden berumur 36-45 tahun yaitu 32,5\% untuk kelompok kasus dan $37,5 \%$ untuk kelompok kontrol. Selanjutnya dapat dilihat pada Tabel 1. Sebagian besar responden pada kelompok kasus proporsi laki-laki lebih tinggi $(57,5 \%)$ dibandingkan kelompok kontrol $(47,5 \%)$. Dari Tabel 2 dapat dilihat juga bahwa sebagian besar responden baik di kelompok kasus dan kontrol berpendidikan tamat SD, yaitu 47,5\%, dan memiliki pekerjaan yang tergolong berisiko yaitu buruh. Pada kelompok kasus proporsi responden yang berprofesi sebagai buruh lebih tinggi $(67,5 \%)$ dibandingkan kelompok kontrol $(65,0 \%)$.

Berdasarkan analisis bivariat menunjukkan bahwa terdapat hubungan yang bermakna $(\mathrm{p}<0,05) \quad$ antara keberadaan kolam, penggunaan kelambu, pemakaian obat anti nyamuk, kebiasaan keluar rumah pada malam hari dan kebiasaan menggunakan pakaian panjang dengan kejadian filariasis di Kelurahan Kuripan Kertoharjo dan Kelurahan Jenggot, Kecamatan Pekalo-ngan Selatan, Kota Pekalongan yang ditunjukkan pada Tabel 3 .

Selanjutnya, dilakukan analisis secara multivariat menggunakan regresi logistik. Karena pada penelitian ini menggunakan desain case control, maka dalam analisis regresi logistik digunakan metode backward conditional. Hasil analisis dengan regresi logistik diperoleh hasil seperti pada Tabel 4. 
Tabel 1. Distribusi responden berdasarkan umur

\begin{tabular}{cccccccc}
\hline No & $\begin{array}{c}\text { Kelompok umur } \\
\text { responden }\end{array}$ & \multicolumn{3}{c}{ Kelompok responden } & \multicolumn{2}{c}{ Total } \\
& & $\mathrm{f}$ & $\%$ & $\mathrm{f}$ & $\%$ & $\mathrm{f}$ & $\%$ \\
\hline 1 & $12-16$ tahun & 0 & 0 & 2 & 5 & 2 & 2,5 \\
2 & $17-25$ tahun & 9 & 22,5 & 5 & 12,5 & 14 & 17,5 \\
3 & $26-35$ tahun & 5 & 12,5 & 13 & 32,5 & 18 & 22,5 \\
4 & $36-45$ tahun & 13 & 32,5 & 15 & 37,5 & 28 & 35 \\
5 & $46-55$ tahun & 9 & 22,5 & 4 & 10 & 13 & 16,3 \\
6 & $56-65$ tahun & 3 & 7,5 & 1 & 2,5 & 4 & 5 \\
7 & $>65$ tahun & 1 & 2,5 & 0 & 0 & 1 & 1,25 \\
\hline \multicolumn{2}{c}{ Total } & 40 & 100 & 40 & 100 & 80 & 100 \\
\hline
\end{tabular}

Tabel 2. Karakteristik identitas responden kelompok kasus

\begin{tabular}{|c|c|c|c|c|c|}
\hline \multirow{2}{*}{ No } & \multirow{2}{*}{ Karakteristik } & \multicolumn{2}{|c|}{ Kasus } & \multicolumn{2}{|c|}{ Kontrol } \\
\hline & & $\mathrm{f}$ & $\%$ & $\mathrm{f}$ & $\%$ \\
\hline \multirow[t]{3}{*}{1} & Jenis Kelamin & & & & \\
\hline & a. Laki-laki & 23 & 57,5 & 19 & 47,5 \\
\hline & b. Perempuan & 17 & 42,5 & 21 & 52,5 \\
\hline \multirow[t]{8}{*}{2} & Pendidikan & & & & \\
\hline & 1). Pendidikan Rendah & & & & \\
\hline & a. Tidak Sekolah & 6 & 15,0 & 0 & 0,0 \\
\hline & b. Tamat SD & 19 & 47,5 & 19 & 47,5 \\
\hline & c. Tamat SLTP & 9 & 22,5 & 13 & 32,5 \\
\hline & 2) Pendidikan Tinggi & & & & \\
\hline & a. Tamat SLTA & 6 & 15,0 & 6 & 15,0 \\
\hline & b. Akademi/PT & 0 & 0,0 & 2 & 5,0 \\
\hline \multirow[t]{9}{*}{3} & Pekerjaan & & & & \\
\hline & 1) Tidak Berisiko & & & & \\
\hline & a. Tidak bekerja & 10 & 25,0 & 14 & 35,0 \\
\hline & b. PNS & 1 & 2,5 & 0 & 0 \\
\hline & c. Swasta & 1 & 2,5 & 0 & 0 \\
\hline & 2) Berisiko & & & & \\
\hline & a. Petani & 1 & 2,5 & 0 & 0,0 \\
\hline & b. Buruh & 27 & 67,5 & 26 & 65,0 \\
\hline & c. Nelayan & 0 & 0,0 & 0 & 0,0 \\
\hline
\end{tabular}


Tabel 3. Rekapitulasi hasil bivariat variabel faktor risiko kejadian filariasis

\begin{tabular}{clccc}
\hline No & \multicolumn{1}{c}{ Variabel } & $P$ value & OR & $95 \%$ CI \\
\hline 1 & Jenis Pekerjaan Berisiko & 0,811 & 1,256 & $0,492-3,209$ \\
2 & Tingkat Pendidikan Rendah & 0,261 & 1.842 & $0,755-4.493$ \\
3 & Tingkat Penghasilan < UMR & 0,585 & 0,636 & $0,215-1,883$ \\
4 & Adanya Keberadaan Kolam & 0,042 & 3,400 & $1,156-9,996$ \\
5 & Adanya Keberadaan Rawa & 1,000 & 2,026 & $0,060-16,562$ \\
6 & Adanya Tanaman Air & 0,615 & 3,162 & $0,315-31,775$ \\
7 & Tidak Ada Ikan Pemakan Jentik & 0,769 & 0,706 & $0,221-2,259$ \\
8 & Tidak Memakai Kelambu & 0,000 & 8,308 & $2,999-23,012$ \\
9 & Tidak Memakai Obat Anti Nyamuk & 0,000 & 35,286 & $7,390-168,476$ \\
10 & Sering Keluar Rumah Malam Hari & 0,003 & 4,500 & $1,731-11,696$ \\
11 & Tidak Menggunakan Pakaian Panjang & 0,001 & 5,741 & $2,154-15,297$ \\
\hline
\end{tabular}

Tabel 4. Ringkasan hasil analisis variabel yang mempunyai hubungan bermakna dengan kejadian filariasis berdasarkan analisis regresi logistik

\begin{tabular}{clccc}
\hline No & \multicolumn{1}{c}{ Variabel } & Pvalue & OR & $95 \%$ CI \\
\hline 1 & Adanya Keberadaan Kolam & 0,042 & 3,400 & $1,156-9,996$ \\
2 & Tidak Memakai Kelambu & 0,000 & 8,308 & $2,999-23,012$ \\
3 & Tidak Memakai Obat Anti Nyamuk & 0,000 & 35,286 & $7,390-168,476$ \\
4 & Sering Keluar rumah Malam Hari & 0,003 & 4,500 & $1,731-11,696$ \\
5 & Tidak Menggunakan Pakaian Panjang & 0,001 & 5,741 & $2,154-15,297$ \\
\hline
\end{tabular}

Tabel 5. Hasil analisis regresi logistik variabel potensial dengan kejadian filariasis

\begin{tabular}{|c|c|c|c|c|c|c|}
\hline \multirow{2}{*}{ No } & \multirow{2}{*}{ Variabel } & \multirow{2}{*}{$\beta$} & \multirow{2}{*}{ Pvalue } & \multirow{2}{*}{$O R$} & \multicolumn{2}{|c|}{$95,0 \% C I$ for $E X P(\beta)$} \\
\hline & & & & & Lower & Upper \\
\hline \multirow[t]{2}{*}{1} & $\begin{array}{l}\text { Tidak Memakai Obat Anti } \\
\text { Nyamuk }\end{array}$ & 3,375 & 0,000 & 29,231 & 5,998 & 142,445 \\
\hline & Constant & $-1,386$ & & & & \\
\hline
\end{tabular}

Berdasarkan hasil analisis dengan regresi logistik (terhadap lima variabel potensial), seperti tampak pada Tabel 4. ternyata hanya satu variabel yang menjadi faktor risiko kejadian filariasis di Kecamatan Pekalongan Selatan, yaitu pemakaian obat anti nyamuk responden dengan koefisien regresi : 3,375 (Tabel 5). Dengan demikian faktor risiko tersebut bisa digunakan untuk merumuskan model persamaan regresi logistik sebagai berikut :

$$
\begin{aligned}
y & =-1,386+(3,375) \\
& =1,989
\end{aligned}
$$

$$
\begin{aligned}
P & =\frac{1}{1+2,718^{-(y)}} \times 100 \\
P & =\frac{1}{1+2,718^{-(1,989)}} \times 100 \\
P & =\frac{1}{1+0,13686} \times 100 \\
P & =\frac{1}{1,13686} \times 100 \\
& =0,880 \times 100 \\
& =88,0 \%
\end{aligned}
$$


dengan demikian, bila seseorang tidak menggunakan obat anti nyamuk pada saat sebelum tidur, maka mempunyai probabilitas menderita filariasis sebesar $88,0 \%$.

\section{Pembahasan}

Tidak memakai obat anti nyamuk memiliki hubungan yang signifikan dan merupakan salah satu faktor determinan yang berpengaruh terhadap kejadian filariasis di wilayah Kecamatan Pekalongan Selatan. Persentase hasil penelitian di Kecamatan Pekalongan Selatan, penderita yang tidak menggunakan obat anti nyamuk yaitu sebesar 95\%. Hal tersebut membuat responden memiliki kecenderungan yang besar untuk tergigit nyamuk penular filariasis.

Hasil penelitian ini sejalan dengan penelitian Garjinto dan Syuhada yang dapat membuktikan bahwa tidak menggunakan obat anti nyamuk pada malam hari merupakan perilaku berisiko terhadap kejadian filariasis. ${ }^{7,8}$

Namun Tidak semua orang dapat menggunakan obat anti nyamuk. Sesuai dengan pernyataan Yatim yaitu berbagai macam obat nyamuk yang beredar dimasyarakat ada yang tidak mengandung bahan aktif dan ada yang mengandung insektisida. Obat anti nyamuk terdiri dari obat nyamuk bakar dan gosok (repellant). Repellant dapat digunakan dibadan, pakaian dan kelambu. Akan tetapi, kelemahan obat nyamuk adalah timbul iritasi pada orang yang sensitif sehingga dapat menimbulkan gangguan kesehatan. ${ }^{9}$

Berdasarkan uraian di atas, selain manfaat dari obat nyamuk yang dapat menghindari dari gigitan ada beberapa orang yang memiliki kulit sensitif menggunakan obat anti nyamuk oles. Bagi orang yang memiliki kulit sensitif dapat melakukan peningkatan pencegahan diri dari gigitan nyamuk lainnya. Bagi penderita dan masyarakat yang tidak memiliki kulit sensitif diharapkan menggunakan obat anti nyamuk ketika senja hingga fajar.

Meskipun berhubungan secara bermakna dengan kejadian filariasis, keempat variabel selain pemakaian obat anti nyamuk tidak berkontribusi secara bermakna dalam analisis regresi logistik. Beberapa hal yang mungkin menyebabkan hal tersebut adalah keterbatasan jumlah sampel untuk analisis regresi logistik dan kemampuan kuesioner penelitian menterjemahkan variabel adanya keberadaan kolam, tidak memakai kelambu, sering keluar rumah malam hari dan tidak menggunakan pakaian panjang

\section{Kesimpulan}

Faktor yang berhubungan secara bermakna dengan kejadian filariasis adalah pemakaian obat anti nyamuk, sedangkan adanya keberadaan kolam, tidak memakai kelambu, sering keluar rumah malam hari dan tidak menggunakan pakaian panjang ditemukan hanya berhubungan pada analisis bivariat.

\section{Ucapan Terimakasih}

Terimakasih kepada masyarakat di Kecamatan Pekalongan Selatan yang bersedia menjadi obyek penelitian dan memberikan kontribusi dalam pengumpulan data.

\section{Daftar Pustaka}

1. Manson's. 2009. Tropical Diseases. Editor : Gordon c. Cook \& Alimuddin I. Zumla, Saunders Elsevier, Twenty$2^{\text {nd }}$ ed., China.pp. 1477.

2. Pusat Data dan Surveilans Epidemiologi Kementerian Kesehatan RI. 2014. Filariasis di Indonesia. 
3. Dinas Kesehatan Kota Pekalongan, 2016. Profil Dinkes Kota Pekalongan.

4. Gordis L, 2000. Case Control and Cross Sectional Studies in Epidemiologi, $2^{\text {nd }}$ ed. Philadelpia, W.B. Saunders Company.pp.140-156.

5. Lameshow S, Hosmers J, Klar J, Lwanga S.K. 1997. Besar Sampel dalam Penelitian Kesehatan, diterjemahkan oleh Pramono, Gadjah Mada University Press, Yogyakarta.

6. BPS Kota Pekalongan. 2017. Profil Kota Pekalongan.

7. Garjito, T. 2013. Filariasis dan Beberapa Faktor yang Berhubungan dengan Penularannya di Desa PangkuTolole, Kecamatan Ampibabo,
Kabupaten Parigi - Moutong, Provinsi Sulawesi Tengah. Jurnal Vektora Volume V No.2.pp.23-30.

8. Syuhada, Y. 2012. Studi Kondisi Lingkungan Rumah dan Perilaku Masyarakat sebagai Faktor Risiko Kejadian Filariasis di Kecamatan Buaran dan Tirto Kabupaten Pekalongan. Jurnal Kesehatan Lingkungan Indonesia. Volume 11 No. 1.pp. 34-40.

9. Yatim, F. 2007. Macam-macam Penyakit menular dan Cara Pencegahannya Jilid 2. Jakarta. Pustaka Obor Populer. 